\title{
Educação e Saúde: Perspectivas para a Autoestima de Crianças Negras no Processo de Escolarização ${ }^{1}$
}

\author{
Veronice Francisca dos Santos ${ }^{2}$ \\ Isabelle Sanches ${ }^{3}$
}

\begin{abstract}
Resumo
O presente artigo trata da promoção da saúde enquanto perspectiva para a construção da autoestima de crianças negras no processo de escolarização da Educação infantil. Dessa forma, se encaminha através das seguintes questões norteadoras: Identificar como os problemas de saúde interferem na construção da autoestima das crianças no processo de escolarização; Verificar se existem políticas públicas educacionais voltadas para a atenção da saúde das crianças nos Centros Municipais de Educação Infantil; Analisar como se dá a articulação entre a educação e a saúde dessas crianças no cotidiano escolar. Para tanto, a abordagem metodológica foi direcionada a partir de uma pesquisa de campo, por meio de uma entrevista semiestruturada com gestores das políticas públicas de educação e do levantamento bibliográfico, considerando o contexto histórico da Educação Infantil, refletindo sobre suas influências nos dias atuais. Nesse sentido, problematiza de que maneira as políticas públicas educacionais direcionam a temática Saúde nos Centros Municipais de Educação Infantil e como este encaminhamento prioriza as necessidades de cada criança, sobretudo, quanto às especificidades do grupo étnico/racial que pertencem. Em síntese, o trabalho se encaminha de modo a verificar de que forma têm sido garantido as crianças da Educação Infantil, a articulação entre educação e saúde e a valorização da sua autoestima para que de fato se desenvolvam plenamente.

Palavras-chave: Saúde; Relações Raciais; Educação Infantil.
\end{abstract}

\begin{abstract}
This article deals with the health promotion perspective as to build self esteem of black children in the education process of children's education. Thus, it is routed through the following questions: how to identify health problems interfere with building self esteem of children in the schooling process; Check for public educational policies aimed at care for children's health at the Centers Municipal Education Child; analyze how the articulation between education and health of these children in school environments. For both, the methodological approach was directed from a field survey, through a semi-structured interviews with managers of public policies on education and literature, considering the historical context of early childhood education, reflecting on its influence on day current. In this sense, it analyzes how public policy drive the educational theme Municipal Health Centers in Early Childhood Education and how this routing prioritizes the needs of each child, especially regarding the specifics of the racial group they belong to. In summary, the work is heading in order to see how they would have been guaranteed the children of the kindergarten, the relationship between education and health and recovery of their self esteem to actually develop fully.
\end{abstract}

Keywords: Health, Race Relations, Child Education.

\section{Introdução}

O presente artigo trata da promoção da saúde como um dos fatores determinantes para a auto-estima de crianças negras no processo de escolarização na Educação Infantil. Nesse sentido, busca identificar como os problemas de saúde interferem de forma negativa

\footnotetext{
${ }^{1}$ Artigo produzido durante a vigência do Projeto "Qualificando a Permanência de Estudantes Cotistas na UNEB" coordenado pela Universidade do Estado da Bahia (UNEB)/ Centro de Estudos dos Povos AfroIndio-Americanos (CEPAIA)/ Secretaria de Promoção da Igualdade (SEPROMI).

${ }^{2}$ Estudante da UNEB - Campus I, do curso de Pedagogia com habilitação em Educação Infantil, bolsista de iniciação científica do Projeto "Qualificando a Permanência de Estudantes Cotistas na UNEB". E-mail: verofsantos@hotmail.com

${ }^{3}$ Orientadora: Mestra em Educação, Psicopedagoga, Professora da UNEB, campus XXI - Serrinha. E-mail: oxobo@hotmail.com.
} 
na construção da autoestima das crianças negras e, conseqüentemente, no seu processo de aprendizagem durante sua trajetória escolar. Assim, a pesquisa se encaminha de modo a verificar de que forma têm sido garantidas as crianças da Educação Infantil, a articulação entre educação e saúde, para que lhes sejam permitidas desenvolverem plenamente as suas potencialidades.

Fundamentado nos Parâmetros Curriculares Nacionais (PCNs), o conceito de "saúde" será analisado neste trabalho na perspectiva da promoção, entendendo a saúde, não apenas como ausência de doença, mas apoiado pelo conceito da Organização Mundial da Saúde (OMS), que acredita ser a saúde "o bem estar físico, mental, emocional, espiritual e de realização plena de uma pessoa".

Reconhecendo os agravos à saúde como variáveis condicionantes no processo de escolarização das crianças da educação infantil, faz-se necessário entender: Quais são os efeitos dessas variáveis para a construção da autoestima das crianças da educação infantil? Desse modo, o trabalho se delineia a partir da investigação sobre como é percebido pelos Gestores das políticas públicas educacionais direcionadas à educação infantil, a articulação entre educação e saúde, e como este encaminhamento está sendo de fato potencializado nos Centros Municipais de Educação Infantil.

Para tanto, a pesquisa aborda três principais eixos temáticos: As políticas públicas direcionadas à Educação Infantil no Brasil; A promoção da saúde enquanto direito fundamental de todo cidadão e a articulação entre Educação e Saúde como determinantes para a construção da autoestima das crianças negras da Educação Infantil.

Indicadores políticos, sociais e econômicos, apontados por pesquisas no Brasil, revelam que a população negra encontra-se em situação de maior vulnerabilidade em relação aos problemas de saúde, principalmente, em se tratando da saúde emocional, que muitas vezes é invisibilizada pela sociedade, mas evidenciados pelas crianças negras na escola através do seu desempenho. Tais problemas interferem negativamente na trajetória escolar dessas crianças trazendo, portanto, sérias conseqüências para a construção da sua auto-estima, revelados através de dificuldades de aprendizagem, que podem levar a evasão escolar, consequentemente, sua exclusão social.

Nesse sentido, concorda Lopes e Castro ao afirmar:

A saúde enquanto conjunto de condições integrais e coletivas de existência é influenciada pela conjuntura política, sócio-econômica e cultural e, em função disso, é essencial considerar que as desigualdades raciais em saúde estão sendo mantidas devido às dificuldades em promover um serviço adequado às 
necessidades de todas as pessoas, sem distinção. (LOPES e CASTRO, 2004, p.64)

Desse modo, ao reconhecer às dificuldades que as crianças negras enfrentam ao longo da vida, a opção por essa pesquisa é mais do que uma escolha minha, é uma questão de postura política, com finalidade de evidenciar os problemas de saúde, que afetam principalmente crianças negras, através da perpetuação da ideologia racista imposta pela sociedade e reproduzida nos espaços escolares. Assim, o presente artigo pretende levantar a temática como prática de problematização e reflexão para o cotidiano escolar, mais precisamente nos Centros Municipais de Educação Infantil (CMEIs).

\section{Políticas Públicas de Educação Infantil no Brasil: Avanços e Desafios}

[...] é um senso comum acreditar que nas escolas todos estejam usufruindo das mesmas oportunidades. (CAV ALLEIRO, 2001, p.143)

Para entender de que maneira acontece à articulação entre Educação e Saúde, no âmbito da política pública educacional direcionada as crianças pequenas torna-se necessário, antes, entender como se configuram as Políticas Públicas de Educação Infantil no Brasil, mais precisamente no âmbito municipal. Investiremos em discutir neste ponto como é percebida pelos gestores dessas políticas públicas direcionadas a educação infantil as concepções de "criança" e "infância", uma vez que é a partir desse entendimento que serão norteados a elaboração dos projetos que contemplem as necessidades das crianças.

Assim, ao analisar o conceito de "criança" e "infância" percebe-se que essas concepções só poderão ser compreendidas, considerando cada momento histórico em que a criança está inserida. Dessas acepções, levanta-se o seguinte questionamento: Terá sido percebida, a criança em suas diversas especificidades ao longo da história?

Os estudos de Philippe Áries (1973, p.50) sobre a História Social da Infância destacam que: "até por volta do século XII, a arte medieval desconhecia a criança. É difícil crer que essa ausência se devesse a incompetência ou a falta de habilidade. É mais provável que não houvesse lugar para a infância nesse mundo".

De acordo com Áries (1973, p.36) desde antiguidade clássica até a Idade Média,

[...] logo cedo a criança era introduzida no mundo do adulto, de cujos jogos e trabalhos participava. Até o século XII a infância era concebida de forma bem diferente da sua representação atual. Os corpos de crianças esculpidos numa miniatura otoniana do século XI, por exemplo, eram reproduções em escala reduzida, de homens adultos (ÁRIES, 1973, p.36). 
Nota-se, que ao longo da história da humanidade, nem sempre a criança era percebida a partir de suas especificidades, visto que na Idade Média inexistia espaço para o sentimento de infância, pois, a criança era confundida como adulto. Desse modo, as pseudo formas de abordagem infantil convergem para uma interpretação apenas física e biológica da criança, interpretando-a como adulto em miniatura. Assim, pode-se perceber a precoce maturação da criança desprovida das suas peculiaridades, o que Zabalza (1998) denomina de "criança-adulto" ou "infância negada".

Apesar de trazer ranços dos períodos anteriores, foi a partir do século XX que começou a surgir um novo, porém, não satisfatório conceito de infância. Segundo Zabalza (1998), a Educação Infantil, bem como a criança, só foi percebida como tal, a partir do século XX, onde a sistematização do ensino infantil assegurado por lei faz nascer um espaço, um lugar específico para a criança, mas que precisa ser repensado, todavia este espaço é passível de limites.

No Brasil, o entendimento do conceito de criança, enquanto portadora de direitos e, portanto, cidadã se dá quando o Estado brasileiro e as diversas organizações da sociedade civil "passaram a reconhecer nas crianças, pessoas com necessidades específicas de desenvolvimento, sobretudo, em sua fase inicial, de zero a seis anos de idade, cujas potencialidades humanas devem ser respeitadas de forma digna, sem discriminação". (BITTAR; SILVA; MOTTA, 2003, p.40.).

Assim, o processo de construção da política de Educação Infantil reconhece como políticas públicas, os direitos de cidadania das crianças de zero a seis anos, quando a partir da Constituição de 1998 assegura o direito da criança à educação no artigo 280, garantindo que: “O dever do estado com a educação será efetivada mediante a garantia de [...] atendendo em creches e pré-escolas, as crianças de o a seis anos de idade". (BRASIL, 1988, p. 138).

Com isso, é importante ressaltar que essa conquista foi assegurada na lei, a partir do entendimento de criança enquanto cidadã, através da pressão dos movimentos sociais para com o Estado, sobretudo, o movimento de mulheres em defesa da visibilidade das crianças enquanto cidadãs, pois, até então só havia programas de caráter assistencialista, mas nada obrigatório que garantisse a oferta educacional desse nível de ensino.

Esse reconhecimento foi importante por desmistificar o conceito limitado que se tinha sobre a infância no país, que era somente o de cuidar em detrimento de educar, entretanto, deve-se destacar a importância das duas relações, entendendo que são duas 
coisas distintas, mas que devem estar interligadas enquanto dever de qualquer instituição educacional de atendimento infantil, de protegê-la e também educá-la.

Além da Constituição de 1988 que incorporou os direitos de cidadãos das crianças, a LDB 9394/96 foi fundamental por regulamentar esses direitos, onde no artigo 29 garante que:

\begin{abstract}
A educação infantil, primeira etapa da educação básica tem como finalidade o desenvolvimento integral da criança de 0 à 3 anos de idade e de 4 à 5 anos sendo atendidos em creches e pré-escolas, em seus aspectos físicos, psicológicos, intelectual e social, complementando a ação da família e da comunidade" (BRASIL, 1996, p.40).
\end{abstract}

Em seus estudos sobre o trato dado a Educação Infantil no Brasil, principalmente no que se refere a questão racial, Cavalleiro aponta que "[...] a experiência escolar amplia e intensifica a socialização da criança" (CAVALLEIRO, 2001, p.17), o que caracteriza as creches e pré-escolas como lócus preferencial para essa socialização. Para Cavalleiro,

[...] o contato com outras crianças da mesma idade, com outros adultos não pertencentes ao grupo familiar, com outros objetos de conhecimento, além daqueles vividos pelo grupo familiar vai possibilitar outros modos de leitura do mundo. (CAVALLEIRO, 2000, p.17).

Sendo assim, reitera Gomes (1990, p.19) que "[...] ao final do processo de socialização a criança não só domina o mundo a sua volta, mas acima de tudo, já adquiriu as características fundamentais de sua personalidade e identidade". Dessa perspectiva é possível inferir que a instituição escolar deverá ser o espaço privilegiado dessa socialização, proporcionando as crianças uma convivência harmoniosa entre todos na escola, respeitando sua cultura, suas particularidades e seu modo singular de vê e pensar o mundo.

Tais afirmativas permitem considerar que a construção da auto-estima das crianças passa pelo processo de socialização. De acordo com Cavalleiro [...] "a identidade é um dos resultados mais importante do processo de constituição social do sujeito [...] assim a identidade resulta da percepção que temos de nós mesmos, advinda da percepção que temos de como os outros nos vêem". (CAVALLEIRO, 2000, p.19). No entanto, os conflitos raciais presentes no cotidiano escolar, sobretudo, da educação infantil, colocam em desvantagem a criança negra do processo de socialização, comprometendo assim sua autoestima durante sua itinerância escolar. 
Ao entender a escola enquanto espaço de socialização devemos compreender que a omissão frente aos problemas familiares, de saúde, de identidade, bem como de outros fatores trazidos pelos alunos para o cotidiano escolar, contribuem para a manifestação e conflitos identitários entre as crianças com seus pares e com outros funcionários da escola.

Assim, não é possível pensar nas creches e pré-escolas como espaço de socialização, sem, contudo, problematizar o sentido da educação, que é antes, entender, acolher as especificidades da criança. Para tanto, uma política pública direcionada para as crianças pequenas deve considerar a criança como um ser integral, como seres que sentem e pensam o mundo de um modo particular, com singularidades e particularidades do universo infantil, mas que também precisam de cuidados, proteções, além de outras necessidades específicas à sua idade. É pensar na criança como um sujeito histórico e social. Um sujeito de identidades que são marcadas, mas que também marcam o mundo a sua volta, por pertencerem a uma cultura, a uma história, a um grupo social.

\section{A Promoção da Saúde Enquanto Direito Fundamental de Todo Cidadão}

"A educação para a Saúde só será efetivamente contemplada se puder mobilizar as necessárias mudanças na busca de uma vida saudável” (BRASIL, 1998, p.69).

Entendendo que os problemas de saúde comprometem no rendimento escolar do aluno, consequentemente, contribuindo para sua baixa auto-estima, a presente pesquisa busca respostas quanto ao encaminhamento das Políticas Públicas Educacionais, na Instância Municipal, principalmente na maneira como é concebida a relação da Educação com a Saúde das crianças nas escolas de educação infantil.

É nesse sentido que se problematiza a importância da Saúde no processo de escolarização das crianças para o desenvolvimento das habilidades e capacidades infantis. Daí, tal conceito é analisado, não mais como saúde versus doenças, mas, a partir do entendimento de saúde enquanto perspectiva da promoção. Para tanto, os Parâmetros Curriculares Nacionais (PCNs) apontam que:

\footnotetext{
A promoção da saúde se faz por meio da educação, da adoção de estilos de vida saudáveis, do desenvolvimento de aptidões e capacidades individuais, da produção de um ambiente saudável. Está estreitamente vinculada, portanto, à eficácia da sociedade em garantir a implantação de políticas públicas voltadas para a qualidade de vida e ao desenvolvimento da capacidade de analisar criticamente a realidade e promover a transformação positiva dos fatores determinantes da condição de saúde. (BRASIL, 1998, p.67).
} 
Com isso, é preciso desmistificar a concepção de saúde apenas como ausência de doença, seu entendimento se relaciona com práticas que promovam o bem-estar das pessoas, em seus aspectos físicos, psicológicos e sociais, enfim, que lhe garantam a qualidade de vida plenamente. Para isso é preciso um encaminhamento de políticas públicas que tenha claro essa concepção de saúde, tendo em vista que ela norteará todas as práticas de educação articuladas à saúde.

Logo, tratar da saúde enquanto promoção é pensá-la a partir de uma política pública que garantida por direito a todo cidadão. Portanto, num estado democrático de direito, como o Brasil, a partir do que rege a Constituição de 1988, na seção II da Saúde, Art.196. "A saúde é direito de todos e dever do Estado, garantido mediante políticas sociais e econômicas...".

Ainda no texto da Constituição, em seu preâmbulo, assegura:

Estado democrático destinado a assegurar o exercício de direitos sociais e individuais, a liberdade, a segurança, e bem-estar, o desenvolvimento, a igualdade e a justiça como valores supremos de uma sociedade fraterna, pluralista e sem preconceitos. (BRASIL, 2005).

Mas, o que se questiona não é uma política que teoricamente preconize a saúde para todos, todavia, que esta de fato seja estendida a todos, principalmente com o enfoque num dos princípios do Sistema Único de Saúde (SUS), que é a equidade. Que se explica pela necessidade de atender diferente aos que necessitam de atendimento diferenciado.

Desse modo, é que se adentra na discussão das especificidades da população negra que historicamente foram e ainda são excluídos das diversas áreas da produção social seja na saúde, na educação, dentre outros âmbitos da vida em sociedade. Para tanto, "coloca pessoas de grupos raciais ou étnicos discriminados em situação de desvantagem no acesso a benefícios gerados pelo Estado e por demais instituições e organizações". (JACCOUD apud BRASIL, 2005).

Nesse sentido, assumir a equidade "representa o aprofundamento do princípio de igualdade formal de todos (as) diante da lei, no qual pessoas e coletividades, que se encontram em circunstâncias especiais ou que são diferentes sejam tratadas de formas especiais ou diferenciadas". (SALVADOR, 2006, p.7). Fazendo isso, estará exigindo o cumprimento da lei, o que só será possível através da observância da sociedade civil e diversos segmentos sociais no acompanhamento e monitoramento de práticas para que se efetive o que é instituído enquanto lei. 
Assim, a elaboração de uma política pública de saúde que contemple as necessidades das crianças da Educação Infantil, deve considerar as especificidades da saúde aos determinados grupos étnicos ao qual pertencem. É possível então situar, que em se tratando do grupo étnico/racial negro, observa-se que pelas precárias condições de saúde a que está submetida essa população, há uma necessidade do direcionamento de políticas específicas a esse segmento, que sofrem pelas desigualdades raciais, inclusive no âmbito da saúde, refletindo diretamente na autoestima das crianças negras.

No entanto, é necessário exigir o encaminhamento de políticas públicas educacionais no Município que atenda as particularidades das crianças, para que se torne de fato potencial nos Centros Municipais de Educação Infantil, através do cuidado com a saúde dessas crianças em fase inicial de desenvolvimento. Haja vista, que na infância, por ser uma fase importante para o desenvolvimento da sua personalidade e na formação do seu caráter, como bem destaca as Diretrizes Curriculares para o Ensino de História Africana:

[...] a autoestima que a criança desenvolve é em grande parte interiorização da estima que se tem por ela e da confiança da qual ela é alvo. Falar em autoestima das crianças pequenas significa compreender a singularidade de cada uma delas em seus aspectos corporais, culturais e étnico-raciais. As pessoas constroem uma natureza singular que as caracterizam como seres que sentem e pensam o mundo de um jeito próprio desde os primeiros anos de idade. (BRASIL, 2007, p.22).

Assim, as práticas de saúde que levem em conta as especificidades dos grupos racialmente discriminados se justificam pela importância, de ressignificar os valores dessa população, que consequentemente refletirá para a sua auto-estima, que é um dos principais requisitos para o bem-estar no entendimento que aqui construímos sobre saúde. De acordo com Cavalleiro (2000, p.19). [...] "a identidade é um dos resultados mais importantes do processo de constituição social do sujeito [...] assim a identidade resulta da percepção que temos de nós mesmos, advinda da percepção que temos de como os outros nos vêem".

\section{Educação e Saúde: Por uma Pedagogia Anti-Racista}

"Não é pressuposto da educação para a Saúde a existência do professor "especialista"; o que se pretende é um trabalho pedagógico cujo enfoque principal esteja na saúde e não na doença". (BRASIL, 1998, p.69)

Tendo como um dos principais objetivos no Plano Municipal de Educação do município, "a Articulação entre Saúde e Educação como garantia do atendimento global e 
desenvolvimento integral e integrado das crianças". Deve-se ao questionamento no que tange as políticas públicas educacionais voltadas para a educação infantil: De que forma está sendo contemplada nas escolas de Educação Infantil tal articulação?

Ao reconhecer a escola como espaço promotor de saúde, principalmente a saúde mental, através da realização de atividades de promoção à saúde, pretende-se problematizar como está sendo de fato potencializado à articulação entre Educação e Saúde no tratamento das crianças pequenas. Dessa maneira, entende-se que tal articulação, pode favorecer tanto a promoção da saúde, no plano emocional, quanto em seus aspectos físicos, sobretudo, no que se refere à primeira que está diretamente relacionada com a autoestima da criança negra, que historicamente traz marcas do longo período de escravidão vivido no Brasil e reproduzido hoje, nas manifestações do racismo presentes nas instituições de ensino.

Tais considerações evidenciam a necessidade de uma política pública de Educação que contemple a temática saúde, devendo esta ser visibilizada no currículo escolar, para que atenda as demandas das crianças. Vale ressaltar que a saúde deve ser entendida aqui, não apenas como identificação de problemas físicos, como pôde ser esclarecida no capítulo anterior, mas como práticas de promoção, para que favoreçam o bem-estar das crianças em sua plenitude.

Em consonância com tais afirmativas, os Parâmetros Curriculares Nacionais (PCNs) enfatizam que:

\footnotetext{
Entende-se Educação para a Saúde como fator de promoção e proteção à saúde e estratégia para a conquista dos direitos de cidadania. Sua inclusão no currículo responde a uma forte demanda social, num contexto em que a tradução da proposta constitucional em prática requer o desenvolvimento da consciência sanitária da população e dos governantes para que o direito à saúde seja encarado como prioridade. (BRASIL, 1998, p.66)
}

No entanto, em que medida as escolas de Educação Infantil estão sendo preparadas para que as práticas de saúde sejam de fato efetivadas? E o sistema educacional, tem dado subsídios às escolas para que de forma autônoma potencialize ações de saúde integrada a educação dessas crianças? E mais, existem verbas específicas voltada para a saúde das crianças da educação infantil? Qual o entendimento dos gestores educacionais sobre a concepção de saúde enquanto perspectiva de promoção? Quais são os efeitos da ausência desta para a autoestima das crianças? 
Buscando uma resposta a respeito de tais questionamentos, foi realizada uma entrevista semi-estruturada com a Coordenadora de Ações Sócio-Educativa da Secretaria de Educação do Município de Salvador (SECULT). Conforme a entrevistada, existe ao nível de política pública municipal, o Programa de Educação para a Saúde Infantil (PESE), que segundo a mesma contempla todos os Centros de Educação Infantil do Município.

De acordo com a Coordenadora ${ }^{4}$ da instituição, o programa é composto por uma equipe multidisciplinar, onde atuam nos CMEIs, diversos profissionais das áreas ligadas á saúde como: Psicólogos, Assistentes Sociais, Enfermeiros etc., que acompanha cada criança individualmente, para diagnosticar a situação de saúde, bem como buscando entender as dificuldades de aprendizagem dos alunos. Assim, ao ser questionada sobre o entendimento de saúde utilizada pelo grupo, a mesma afirmou: "Vejo a criança como um todo, não existe separação por raça/cor, a criança não pode ser enxergada pela cor e sim pela alma, pelo ser criança."

Dessas afirmativas, pode-se levantar o seguinte questionamento: E os problemas que afetam diretamente o grupo racial pertencente à criança negra, a exemplo da violência simbólica nas práticas de bullying e outras doenças psíquicas permeadas no cotidiano escolar, como elas refletem no seu autoconceito? Será que as crianças são vistas sem levar em consideração a cor da pele? Todas devem ser tratadas de maneira igual, mas o que é igualdade?

Estas inquietações são para provocar uma reflexão e um diálogo mais profundo entre todos os envolvidos no processo de escolarização das crianças, estendendo ao professor que tem contato direto com as mesmas, em busca de discussão sobre as condições de saúde destas crianças, principalmente aos problemas que refletem na sua auto-estima. Dessa maneira, os Parâmetros Curriculares Nacionais (PCNs) apontam que

\footnotetext{
Ao educar para a saúde, de forma contextualizada e sistemática, o professor e a comunidade escolar contribuem de maneira decisiva na formação de cidadãos capazes de atuar em favor da melhoria dos níveis de saúde pessoais e da coletividade. (BRASIL, 1998, p.60)
}

Tais afirmações são também problematizadas por Lopes (2004), quando afirma que “a formação do aluno para o exercício da cidadania compreende a motivação e a

\footnotetext{
${ }^{4} \mathrm{O}$ nome aqui não será citado tendo em vista o resguardo da identidade da interlocutora.
} 
capacitação para o autocuidado, assim como a compreensão da saúde como direito e responsabilidade pessoal e social". Portanto, por ser a escola, a representação dos valores, das crenças e dos costumes individuais e coletivos, deverá ser o lócus preferencial para a realização de práticas que promovam a socialização e o acolhimento das diversas culturas existentes no cotidiano escolar, visando o seu pleno desenvolvimento para o exercício da cidadania.

Para isso, é necessário desconstruir algumas inverdades que ainda estão no inconsciente coletivo e que atrapalham a realização de um trabalho que de fato direcione uma política de educação e saúde que atenda a todos e a cada um dentro de suas particularidades. Pois, voltando a problematizar sobre a entrevista com a coordenadora da SECULT, percebe-se que de maneira sutil, ainda que não de forma intencional ela revela uma negação dos conflitos raciais na escola.

Pois, apesar de dizer que existe um programa de Anemia Falciforme - doença que atinge em grande parte negros e negras - que visa identificar o problema nas escolas destacando a importância deste. A entrevistada enfatiza que:

[...] ao contrário, o que nós deixamos muito claro no programa é um incentivo para que não haja distinção de cor, pois, a criança do olho azul deverá ser tratada da mesma forma que a criança negra e vice-versa, não há separação.

Mas, o que se pretende mesmo não é uma distinção de cor, nem mesmo um tratamento melhor, para um ou para o outro. O que se problematiza aqui é sobre o racismo, uma questão que ainda não foi resolvida pela sociedade brasileira e que muito facilmente é propagada no cotidiano escolar, tanto entre as crianças com seus pares, quanto na relação das crianças com outros profissionais da escola, acarretando em graves problemas de saúde.

Para tanto, o que se chama a atenção é para que se possa assumir um dos princípios básicos do SUS, que é sobre a equidade. E assumir tal princípio é "requisito para a melhoria das condições que afetam diretamente a qualidade do ensino" (LIBÂNEO, 2004, p.378). No entanto, cabe aos/as gestores/as das políticas educacionais, bem como professores e demais profissionais da escola, em problematizar as questões raciais existentes no ambiente escolar, desconstruindo mentalidades racistas para torná-la de fato um espaço democrático. 


\section{Considerações Finais}

Depreende-se desse trabalho que a Educação brasileira, desde a sua gênese até os dias atuais, está umbilicalmente atrelada, a uma política universalizadora e não fomentadora da autonomia das crianças. O próprio processo histórico da Educação Infantil no Brasil denuncia práticas assistencialistas que não consideram as potencialidades das crianças como um todo.

Apesar disso, reconhece-se que houve sucessivos avanços com a implementação de políticas públicas de educação infantil no Brasil. Porém, estes pecam se pela limitação de suas próprias leis e decretos, ou quando não fornece meios de aplicabilidades, em que pese os avanços significativos no contexto educacional, sobretudo, a partir da Constituição Federal de 1988, que incorporou os direitos de cidadania das crianças, a Lei de Diretrizes e bases da Educação Nacional, os Referenciais Curriculares Nacionais para a Educação Infantil, dentre outros.

As políticas educacionais direcionadas à Educação Infantil sobre as condições de saúde das crianças, para o seu pleno desenvolvimento, ainda não conferem uma educação que promovam as oportunidades de igualdade entre todos no ambiente escolar. Assim, ao acreditar nas crianças como ser em potencial, a escola como lócus privilegiado para o desenvolvimento das capacidades infantis, possa proporcioná-la, ao seu pleno bem-estar em seus aspectos físicos, psicológicos, sociais, familiares, para que preparem seu aluno de forma integral para os problemas por eles enfrentados durante toda sua trajetória de vida.

Contudo, ficou nítido no presente trabalho, tanto em relação às consultas bibliográficas, quanto na pesquisa de campo, uma insuficiência de intersetorialidade de políticas na gestão pública e do trato pedagógico sobre as questões raciais nas escolas de educação infantil, que as reconheçam como questões de saúde. Para tanto, esse reconhecimento só será de fato potencializado através da cobrança e da vontade política da sociedade civil e das escolas públicas de educação infantil, para mudar o quadro das desigualdades raciais em saúde e que interferem negativamente no aprendizado da criança no cotidiano escolar.

Assim, o presente trabalho visa contribuir para o aprofundamento do debate acerca das relações entre saúde e educação, ampliando-se o debate para as relações raciais por entender as especificidades de cada aluno. Nesse sentido, chama a atenção do papel das autoridades governamentais para o compromisso na transformação social, através da efetivação de políticas públicas de saúde direcionadas a educação infantil, que contemplem as necessidades individuais e coletivas, por entender as crianças como sujeitos que são 
marcadas, mas que também marcam o mundo a sua volta, com seu jeito singular de vê, pensar e entender o mundo.

Contudo, espera-se com esse trabalho exaltar a importância da discussão voltada para a educação das relações étnico-raciais, sobretudo, na educação infantil, por ser a primeira etapa da educação formal. Reconhecendo assim, a relevante contribuição desse debate para a escolarização de crianças negras durante toda a sua trajetória escolar, direcionando dessa forma para práticas de uma educação anti-racista.

Portanto, faz-se necessário que haja por parte de todos os profissionais da escola uma formação que atenda as necessidades e as particularidades das crianças, ao mesmo tempo em que as reconheçam como pertencentes a uma cultura, a uma história e a um grupo social. Sendo assim, espera-se que a escola esteja pautada numa perspectiva pluricultural, que acolham a todas as crianças, sem quaisquer tipos de discriminação e que valorizem todas as culturas evidenciadas na escola, tornando um ambiente escolar agradável e acolhedor.

Por fim este trabalho pretende contribuir para a autoestima das crianças negras da educação infantil a partir do trabalho de articulação de Educação e Saúde no cotidiano escolar. E mais, chamar a atenção da responsabilidade de todos os envolvidos no processo de escolarização das crianças pequenas para a promoção de práticas equitativas no ambiente escolar, direcionando a todos para uma educação anti-racista.

\section{REFERÊNCIAS}

1. ARIÈS, Philippe. O Sentimento da Infância e a Descoberta da Infância. História

2. Social da Criança e da Família / Philippe Áries: Trad. Dora Flaskman, segunda edição. - Rio de Janeiro: Guanabara,1981.

3. BATISTA, Luís Eduardo e KALCKMANN, Suzana(org). Experiências desiguais ao nascer, viver, adoecer e morrer: tópicos em saúde da população negra no Brasil. In: LOPES, Fernanda. Seminário de Saúde da População Negra Estado de São Paulo, 2004.São Paulo: Instituto de Saúde, 2005.

4. BRASIL. Lei ñ 9.394, de 20 de dezembro de 1996. Estabelece as diretrizes e bases da educação nacional, Casa Civil da Presidência da República, Brasília, DF, Disponível em: $<$ http://portal.mec.gov.br/arquivos/pdf/ldb.pdf $>$. Acesso em: 18 out. 2009.

5. BRASIL. Constituição (1988). Constituição da República Federativa do Brasil: Promulgada em 5 de outubro de 1988. Casa Civil da Presidência da República. Subchefia para Assuntos Jurídicos, Brasília, DF, Disponível em: <http://www.planalto.gov.br/ccivil_03/constituicao/constitui\%C3\%A7ao.htm> Acesso em: 15 jan.2010. 
6. BRASIL. Ministério da Educação e do Desporto: Secretaria de Educação Fundamental. Referencial Curricular Nacional para a Educação Infantil. V.1. Brasília: MEC/SEF, $1998 . \quad$ p.35. Disponível em: <http://portal.mec.gov.br/seb/arquivos/pdf/rcnei_vol1.pdf. Acesso em: 09 out. 2009.

7. BRASIL. Ministério da Educação e Cultura. Secretaria de Educação Fundamental. Parâmetros Curriculares Nacionais: apresentação dos temas transversais, Pluralidade Cultura e Saúde. Brasília: MEC/SEF,1997 a.

8. BRASÍLIA. Conselho Nacional de Educação. Diretrizes Curriculares Nacionais para a Educação das Relaçooes Étnicos-raciais para o Ensino de História e Cultura Afro-Brasileira e Africana. Brasília, DF, CNE, 10 de março de 2004. Petronilha Beatriz Gonçalves e Silva (Relatora).

9. CAVAlLEIRO, Eliane. Do silêncio do lar ao silêncio escolar: racismo, preconceito e discriminação na educação infantil. São Paulo: Contexto, 2000.

10. CAVALLEIRO, Eliane (Org.). Racismo e Anti-racismo na educação: repensando nossa escola São Paulo: Selo, 2001.

11. CONSTITUCIONAL, Emenda. República Federativa do Brasil, Ano 05/09/05 Local,mês/Ano.Disponível em: <http://www.planalto.gov.br/ccivil_03/constituicao/ constitui\%C3\%A7ao.htm>. Acesso em: 15/ 01/ 2010.

12. GOMES, Nilma Lino. A mulher negra que vi de perto. Belo Horizonte: Mazza. Edições, 1995.

13. JACOOUD, Luciana. O Combate ao racismo e à desigualdade: O Desafio Das Políticas Públicas de Promoção da Igualdade Racial. In: THEODORO, Mário.(org.). As políticas públicas e a desigualdade racial no Brasil 120 anos após a abolição. Brasília. Ipea, 2008.

14. LIBÂNEO, SOUSA, Sandra M. Zákia L. Avaliação do Rendimento Escolar como Instrumento de Gestão Educacional. In: OLIVEIRA, Dalila (Org.). Gestão Democrática da Educação. Rio de Janeiro: Vozes, 1997.

15. LIMA, Maria Nazaré Mota de. (org). Escola Plural: A Diversidade está na sala. Formação de Professoras em História e Cultura Afro-brasileira e Africana. São Paulo: Cortez; Brasília: UNICEF; Salvador, BA: CEAFRO, 2006.

16. MOURA, Clovis. Formas de Resistência do Negro Escravizado e do Afro Descendente. In: MUNANGA, Kabenguele (org.). História do Negro no Brasil - O negro na sociedade brasileira: Resistênca, participação, contribuição. Brasília/CNPq: Fundação Palmares.

17. 2004.

18. MUNANGA, Kabengele. Racismo, discriminação racial e ações afirmativas: a sociedade atual. In: MUNANGA, Kabengele; GOMES, Nilma Lino (org.). Para 
entender o negro no Brasil de hoje: história, realidades, problemas e caminhos. São Paulo: Global: Ação Educativa Assessoria, Pesquisa e informação, 2006.

19. MUNANGA, Kabengele. Conceito e história da mestiçagem. In: MUNANGA, Kabengele. Rediscutindo a mesticagem no Brasil: identidade nacional versus identidade negra. 3. Ed. Belo Horizonte: Autêntica, 2008.

20. RUSSEF, Ivan; BITTAR, Mariluce (orgs.). Educação Infantil: política, formação e prática docente. Campo Grande: UCDB, 2003. SALVADOR. Cartilha Quilombola n³. Quilombos Urbanos de Salvador e a Saúde da População Negra. 2004, p.07.

Artigo recebido em: 24/03/2011

Aceito para publicação em: 22/06/2011 